\title{
Using ICT to Improve the Education of Students with Learning Disabilities
}

\author{
Tas Adam and Arthur Tatnall \\ 1 School of Information Systems, \\ Victoria University, Melbourne, Australia \\ Tas.Adam@vu.edu.au \\ 2 Centre for International Corporate Governance Research \\ Victoria University, Melbourne, Australia \\ Arthur.Tatnall@vu.edu.au
}

\begin{abstract}
The potential of Information and Communications Technology in all forms of education has been well demonstrated. In this paper we examine how ICT can improve the education of students with learning disabilities (LD). We will begin by examining the nature of learning disabilities and discussing the different approaches to schooling for students with LD. Learning models have evolved over recent years in response to many factors including the advent of technology in education. This is particularly important in this arena where technology can make a significant difference to educating these students, but only if it is used appropriately. The paper then looks at a case study of use of ICT in a school catering for students with LD.
\end{abstract}

\section{Children with Learning Disabilities}

The term Learning Disability (LD) is used to refer to any retardation, disorder, or delayed development in one or more of the processes of speech, language, reading, writing, arithmetic, or other school subjects resulting from a psychological handicap caused by a possible cerebral dysfunction and/or emotional or behavioural disturbances [1-3]. Learning disabilities are not the result of mental retardation, sensory deprivation, or cultural and instructional factors [4]. Sometimes the alternative term Special Needs is used in regard to education of children, but this term can, however, refer to many different things spanning both physical and mental needs. In this paper we will refer to children with the particular type of special need resulting from learning disabilities.

Over the years a number of LD definitions have been proposed, but none has emerged as an unequivocal favourite [5]. Presently, the two definitions enjoying the greatest support are the legislative definition found in the Individuals with 
Disabilities Education Act [6] and the one proposed by the National Joint Committee on Learning Disabilities [7], which is a consortium of representatives from organisations interested in LD. A more recent definition comes from the Learning Disabilities Association of Canada [8] who define Learning Disabilities as: "a number of disorders which may affect the acquisition, organization, retention, understanding or use of verbal or nonverbal information. These disorders affect learning in individuals who otherwise demonstrate at least average abilities essential for thinking and/or reasoning. As such, learning disabilities are distinct from global intellectual deficiency." The Association suggests that learning disabilities result from impairments in one or more processes related to perceiving, thinking, learning or remembering, and include language processing; phonological processing; visual spatial processing; processing speed; memory and attention; and executive functions [3]. They go on to note that LD varies in severity and may interfere with the acquisition and use of oral language, reading, written language and mathematics [8].

The prevalence of LD in Australia is around $10-15 \%$ of students at the primary levels, and is still significant at the secondary level at 5-10\% [9-11]. These figures show a similar rate to the USA and other countries [7].

A significant issue that has concerned many education authorities around the world is whether students with learning disabilities should receive their education in mainstream classrooms or in some form of special schools. A number of researchers support the view that students with LD require an alternative approach to their learning, while others claim that it is best to integrate these students with mainstream classes [12]. While many integration and remedial programs have proved ineffective for this group of students [1]. The literature shows that in some selected fields, such as mathematics and social studies, specialist instruction has had little success [13-15]. Overall however, there is considerable evidence to support the view that of separate schools should exist for students with learning disabilities [16].

\section{ICT and Education of Students with Learning Disabilities}

Many studies over the last 30 years have shown that technology can play a significant role in any work with specific disadvantaged groups such as the blind and those with movement disabilities. It can do so in the provision of media to facilitate communication and education [17], but also in other learning. Studies have also investigated how information and communications technologies (ICT) can influence the education of students with LD and have shown that this technology can play an important and useful role [18, 19].

Over the last few years the Victorian government has begun to place considerable emphasis on the importance and availability of ICT for students with LD [2]. At a seminar in 2005 the Minister reiterated a major policy to support Victoria schools in various ways so that students would enhance their learning and employability position prospects. This was also to apply to students with LD [20]. Also in recognition of the potential role of ICT the Australian Commonwealth Government has recently announced a plan to equip every senior school student with a laptop computer. 
Schunck and Nielsson [21] outline three stages in the use of technology in education. This stage (Figure 1) is the paradigm of the verbal tradition (what Schunck and Nielsson call the paradigm of the past), that is characterised by a verbal flow of information streaming from the teacher directly to the students [2].

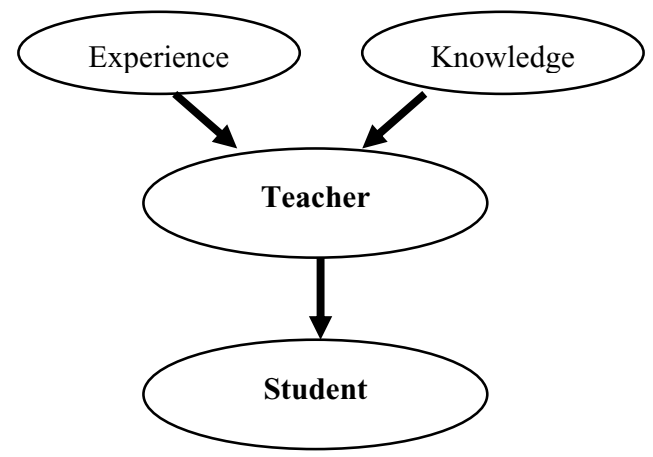

Figure 1: Paradigm of the verbal tradition

In the second paradigm that Schunck and Nielsson call the paradigm of today, communication is two way and students also communicate amongst themselves, but the teacher is really still at the centre. It is a paradigm where both teacher and student share responsibility, but the teacher remains the main source of information.

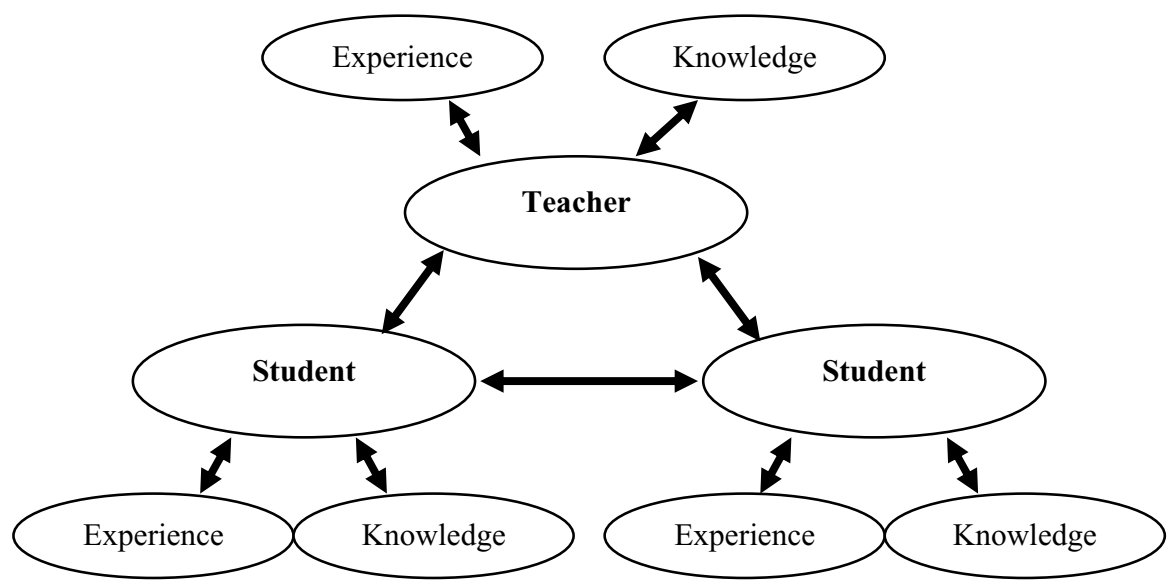

Figure 2: Paradigm of the teacher-centred classroom

The third paradigm (Figure 3 below) - what Schunck and Nielsson call the elearning paradigm, differs in placement of a knowledge base at its centre. It gives both students and teachers important roles where the teacher acts as a consultant for students on where information can be obtained and communicates knowledge and experience to the students. This is a technology-based paradigm in which students make extensive use of ICT to obtain information and experiences. The learning responsibilities of the students here are for 'searching', rather than 'receiving' [2]. 


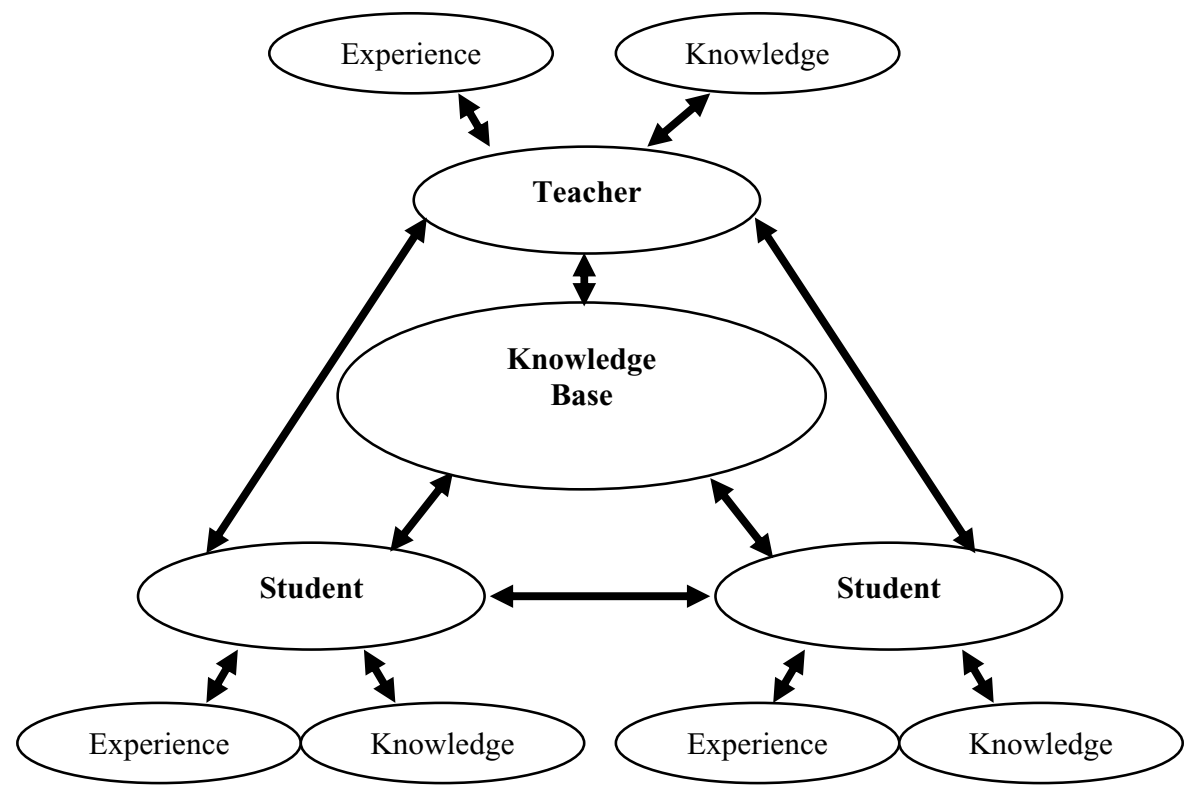

Figure 3: The e-learning paradigm

\subsection{The Concord School Transition Centre}

Concord is a specialist school which caters for students with mild to moderate intellectual disability. The students come from diverse socio-economic backgrounds and are between the ages of 5 and 18 years. The school has 86 teaching and ancillary staff and an enrolment of 270 students [22]. Enrolment is dependent on eligibility criteria that have been determined by the Victorian Department of Education and Training. Concord supports integration into or from mainstream schools and offers support services to parent, careers and students. These include social workers, guidance officers, speech therapists and visiting teacher services [22].

The Concord School Transition Centre caters for approximately 60 students from Years 10-12. Three learning programs are delivered here offering an applied learning curriculum. In Year 10, students complete a pre-transition learning program designed to prepare them for post-compulsory schooling. In Years 11, 12 are four groups each of approximately twelve students. Students in three groups complete their VCAL (Victorian Certificate of Applied Learning) award over two years. The fourth class has a Special Needs Learning Framework (SLNF) learning program [22], also over two years, developed by Concord Transition Centre staff to meet the needs of the high support students. An interesting ICT initiative is the One-to-One (121) program that will require the school to invest in a computer (lap-top or desktop) for each of these students, as well as other accompanying software and hardware. The 121 ICT project offers opportunities for students to use technology that will improve their literacy output, access and exposure to technology as well as increasing engagement [2]. VCAL students have demonstrated that they experience 
learning success and engagement when given access to technology, and lack of ongoing access to such technology that is the primary area of concern. Observations of student behaviour and students' expressed learning preferences over the past twelve months have significantly raised awareness regarding need to access ICT [23].

Presently the VCAL students at Concord School develop electronic portfolios, and it is hoped that access to 121 ICT will further support the students' skills and abilities in this area. The implementation of 121 ICT classroom environments will also require development of a new shared curriculum and a new pedagogical focus [24] and necessitate moving away from autonomous teaching practices and incorporating new approaches to teaching [25], including a teacher commitment to personalised learning for students and where learning experiences are student directed - Schunck and Nielsson's e-learning paradigm. Sustained transformation will require that staff commit to undertaking the necessary professional development required in order to prepare for these changes [25].

\subsection{ICT and Collaborative Learning at Concord School}

In moving towards Schunck and Nielsson's e-learning paradigm, the School hopes to empower its students by using student directed collaborative tools to enable them to find content and pursue personal interests using the Internet. By introducing these Web 2.0 tools and teaching students to use them the School is aiming to give them a voice so that they can make choices and create an online presence through content creation [26]. It is expected that the students will create and publish content and also respond to the content creation of others. Created content can be aggregated to show progress and richness and depth of learning and students can respond to the work of others, provide feedback, and learn through their interactions with others online. Not only are students learning but they are also learning how to be independent learners.

For the last two years Concord School has trialled use of social software (Lumil, WordPressMU, ccHost, Urdit, Gregarius and Scuttle), networked learning activities and practices. These tools and technologies are complimentary and are used concurrently as much of the power of social software is its interoperability.

The move towards web based collaborative practices and activities has resulted in a change in teaching practice. Students have begun using these services for leisure activities and free time, due to their ease of use and breadth of content. Priorities and activities of networked learning and social software are a good fit with Concord's curriculum focus of Personal Learning, and Concord's enthusiastic teaching staff is no doubt the key to the acceptance of these technologies and practices [26].

Selection of software and student activities is framed by how it can be shared on the web, and as small elements sp that students can build on the work of others. Given the breadth of curriculum innovation that has occurred, and the sense of success that has accompanied these changes, many teachers have found renewed energy and excitement to try new ideas and approaches in their use of ICT [26]. Professional discussions are no longer bound by a commitment to previous practices and commitments but are focussed on increasing student learning outcomes. In additional to changes to the curriculum, Concord has begun implementing a webbased approach to student assessment and knowledge management. 


\section{Methodology}

Our research has involved examining how several schools that cater for students with LD have made use of ICT in their curricula. This has involved participant observation, interviews, surveys and discussions as well as an examination of the technology that might potentially be useful here. In an area like this that depends on both human and non-human actors, actor-network theory (ANT) [27] can provide a useful framework. ANT considers equally contributions of human and non-human actors, reacting against the idea that characteristics of humans and social organisations distinguish their actions from the inanimate behaviour of technological objects. It offers a socio-technical approach in which neither social nor technical positions are privileged, denying purely social or technical relations are possible.

The actors involved in this technology-based learner interface include: students, parents, teachers, the Web, computers, Education Department policies, technology policy, school and classroom environments, learning approaches and paradigms, methods of instruction, engagement methods, thinking processes, technology infrastructure-bandwidth, curriculum, Web curriculum, Internet resources, digital libraries [1]. Figure 4 shows some of the main actors and interactions involved.

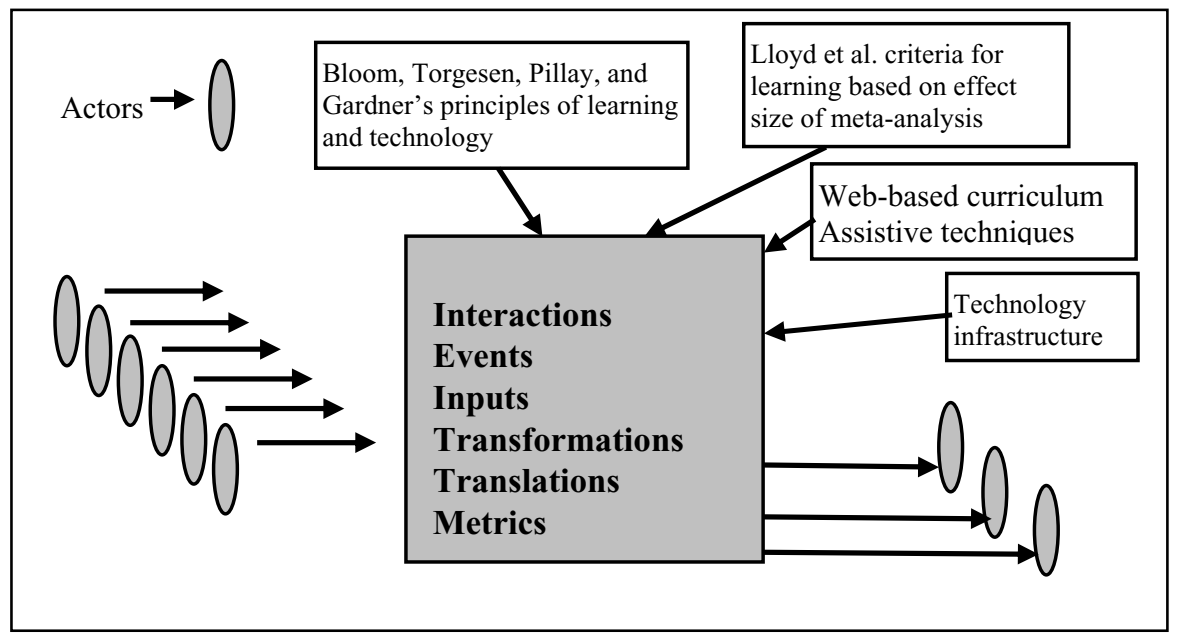

Figure 4: Actors, networks and interactions

In an ANT framework, actors are seen to contest and negotiate with each other in an attempt to influence the final outcome in a direction of their own liking. The Education Department, for example, might want ensure that all schools offer a similar level of service to students and to ensure their accountability. The parents of a student with LD, on the other hand, would want the best for their own child regardless of what was going on in other schools. The technology (both hardware and software) itself acts in the way it was designed, both intentionally and unintentionally, to act. In utilising an ANT approach, this study involved interviews and discussion with the actors or, in the case of the technology, with those who speak for them. The main advice on method suggested by Latour [28] is to 'follow the actors' and to let them set the framework and limits of the study themselves. 


\section{Conclusion}

For educational purposes, much of the power of the Internet lies in is its ability to foster virtual learning communities, and LD students are no exception to this. The difference this technology can make to these students in many ways is remarkable. ICT certainly offers students the capacity to construct their own learning experiences, and our investigations suggest that this applies also to students with Learning Difficulties. One of the problems that this group face, however, is not being a big enough political lobby to be able to obtain the funding and support that they deserve and that could make a huge difference to their education.

\section{References}

1. Adam, T. and A. Tatnall. Using Web-Based Technologies to Enhance the Learning of Students with Learning Disabilities who Live in Regional Areas. in IT in Regional Areas (ITiRA-2002). 2002. Rockhampton, Australia: CQU.

2. Adam, T., A. Rigoni, and A. Tatnall, Designing and Implementing Curriculum for Students with Special Needs: A Case Study of a Thinking Curriculum. Journal of Business Systems, Governance and Ethics, 2006. 1(1): p. 49-63.

3. Adam, T. and A. Tatnall. Building a Virtual Knowledge Community of Schools for Children with Special Needs. in Information Technologies for Education and Training (iTET). 2007. Charles University, Prague: ETIC Prague.

4. Kirk, S.A., Educating exceptional children. 1962, Boston: Houghton Mifflin.

5. Tucker, J., L.J. Stevens, and J.E. Ysseldyke, Learning Disabilities: the Experts Speak Out. Journal of Learning Disabilities, 1983(16): p. 6-14.

6. IDEA, Individuals with Disabilities Education Act. 1997, United States.

7. NJCLD, Learning disabilities: Issues on definition revised, in Collective Perspectives on Issues Affecting Learning Disabilities. 1994, PRO-ED: Austin, TX. p. 61-66.

8. Learning Disabilities Association of Canada. Official Definition of Learning Disabilities. 2002 [cited May 2007]; Available from: http://www.ldactaac.ca/Defined/defined_new-e.asp.

9. ABS, Commercial Training Providers, Australia - 1994. 1996, Australian Bureau of Statistics: Canberra. p. Catalogue No. 6352.0.

10. ABS, Education and Training Experience Australia. 1997, Australian Bureau of Statistics: Canberra. p. Catalogue No. 6278.0.

11. Ministerial Council on Education; Employment; Training and Youth Affairs, National Schools Statistics Collection 1989-97. 1997, Australian Bureau of Statistics: Canberra.

12. Bulgren, J., Effectiveness of a concept teaching routine in enhancing the performance of LD students in secondary-level mainstream classes. Learning Disability Quarterly, 1998. 11. 
13. Swanson, L., Cognitive processing Deficits in poor readers with symptoms of reading disabilities: More alike than different. Journal of Educational Psychology, 1999. 91(2.): p. 321-333.

14. Klinger, J.K., Outcomes for Students With and Without Learning Disabilities in Inclusive Classrooms. Learning Disabilities Research \& Practice, 1998. 13(3): p. 153-161.

15. Johnson, G., R. Gersten, and D. Carmine, Effects of Instructional Design Variables on Vocabulary acquisition of LD students: A Study of computerassisted Instruction. Journal of Learning Disabilities, 1998. 20(4).

16. Adam, T. and A. Tatnall. Using Information and Communication Technologies to Enhance the Learning Outcomes of a Virtual Community of Students with Learning Disabilities. in ACIS 2003. 2003. Perth: ACIS.

17. Poon, P. and P. Head. Computers Assisting People. in 1st Pan Pacific Computer Conference. 1985. Melbourne: Australian Computer Society.

18. Quinn, C.N., Designing an Instructional Game: Reflections for Quest on Independence. Journal of Education and Information Technologies., 1996. 1(1): p. 251-269.

19. Pillay, H., Cognition and Recreational Computer Games: Implications for Educational Technology. Journal of Research on Computing in Education, 2000. 32(1): p. 32-41.

20. Adam, T., A. Rigoni, and A. Tatnall. The Application of ICT in the Development of a Thinking Curriculum: a Pilot Project for Students with Special Needs. in 1st Victoria University Business Research Conference. 2005.

21. Schunck, L.G. and L. Nielsson. Varying Learning Paradigms. [Web publication] 2001 [cited June 2003]; Available from: www.fcfu.dk/artikel/paradigm.htm.

22. Concord School. School Profile. 2007 [cited November 2007]; Available from: http://www.concordsch.vic.edu.au/web/.

23. Caldwell, B. Global Transformations. 2005 [cited November 2005]; Available from: http://www.educationaltransformations.com.au/publications.php.

24. Davies, B. and B.J. Davies, Strategic Leadership, in The Essentials Of School Leadership. 2005, London: Paul Chapman Publishing and Corwin Press.

25. Southworth, G., Learning-Centred Leadership, in The Essentials Of School Leadership. 2005, London: Paul Chapman Publishing and Corwin Press.

26. Adam, T., A. Tatnall, and R. Olsen. Catching Students and Teachers in the Web. in $W e-B$ 2007. 2007. Melbourne: Victoria University.

27. Latour, B., The Powers of Association, in Power, Action and Belief. A New Sociology of Knowledge? Sociological Review monograph 32, J. Law, Editor. 1986, Routledge \& Kegan Paul: London. p. 264-280.

28. Latour, B., Aramis or the Love of Technology. 1996, Cambridge, Ma: Harvard University Press. 